\title{
The Linkage of Government Bond and Stock Markets in China
}

\author{
Ming FANG \\ Associate Professor, Department of Finance \\ Fuzhou University of International Studies and Trade \\ No.28, Yuhuan Road, Shouzhan New District, Changle, \\ Fuzhou City, Fujian, China \\ gordonming999@qq.com
}

\begin{abstract}
This paper examines the linkage of government bond and stock markets in China. We illustrate these ideas in simple empirical settings, implementing the relatively techniques from quantile regression. The analysis of extreme quantiles observes that the linkage of government bond and stock markets is negative while the stock market goes down. Our contribution provides the ability to estimate the diversification effects to international investors that are attributed to the government bond and stock market in China. This study has important implications for risk management and asset allocations during extremes. Furthermore, the finding is also important for international asset pricing since the exposure to the joint extreme risk and thus should be included in pricing international assets.
\end{abstract}

Keywords-government bond; quantile regression; linkage; diversification

\section{INTRODUCTION}

A good understanding of the linkages between these different financial assets is an important consideration when designing investment portfolios. Investors would require information about the relationships of asset returns in order to implement dynamic portfolio rebalancing strategies. For example, if the returns from two assets tend to be negatively correlated in some circumstances but are strongly positively correlated in others, this has clear implications for portfolio diversification. Strong linkages among different assets were observed more strongly during periods of market stress. We focus on asset market linkages during crisis periods and examine whether the propensity for these extreme linkages between different asset classes has changed over time. Investors would require information about the relationships of asset returns in order while access their assets allocation. A good understanding of the linkages between these different financial assets is an important consideration when designing investment portfolios. Consequently, it is important for portfolio managers to be able to identify the circumstances in which there may be a change in the relationships between the returns of different assets.

During a financial crisis, investors become more risk averse and consequently decrease their exposure to risky assets. In periods of market stress, the financial press interprets extreme and inverse market movements across financial assets. Any proposed benefits from portfolio diversification across

\author{
Chiu-Lan CHANG* \\ *Corresponding author, the International College, \\ Xiamen University \\ Xiang'an South Road, Xiang'an District, Xiang'an Campus of \\ Xiamen University, Xiamen, Fujian, China \\ clchang@xmu.edu.cn
}

financial assets depend on the dependence between their returns. Several studies have investigated the linkage of bond and stock markets and find that stock and bond returns exhibit substantial time variations in the short term, including sustained periods of negative correlation (Gulko, 2002; Fleming et al., 2003; Hartmann et al., 2004; Goyenko and Sarkissian, 2010). Among studies that examine the relationship between stock and bond markets, Abel (1988) constructs an equilibrium model for the prices of the aggregate stock and riskless one-period bonds, and Barsky (1989) develops an general equilibrium model which explores the possible roles of increased risk and reduced productivity growth in influencing the behavior of bond and stock prices. Hartmann et al. (2004) suggest that the co-movement is approximately as frequent as the flight-to-quality from stocks to bonds in developed nations. Connolly et al. (2005) find that bond returns tend to be high in relation to stock returns when the stock market risks are rising. Similarly, Gonzalo and Olmo (2005) and Chordia et al. (2005) report a negative association between stock and bond returns during periods of turmoil. Piplack and Straetmans (2010) provide evidence that the relationships between the returns on different assets change during periods of market stress. Chan et al. (2011) examine the linkages between five different asset classes: stocks, bonds, oil, gold and real estate assets. Kemper et al. (2012) investigate the benefits of diversification by studying the co-movements of stocks and bonds in portfolio returns and find greater negative correlations during times of market distress.

We examine the linkage across two financial assets: stocks and government bonds. In this study we apply the application of the quantile regression method. When such a response exhibits strong patterns of heterogeneity, the quantile regression approach is expected to provide a more comprehensive picture of different spending behaviors because it allows the coefficients to vary over the whole spectrum distribution of the bond returns. Previous studies have generally used ordinary least square model to value the linkage of government bond and stock markets, there we use the quantile regression model. This method provides us a more flexible approach to obtain a more complete picture of the of government bond and stock markets which achieve an accurate evaluation at extremes. The theory of quantile regression was developed by Koenker and Bassett (1978) and it has been applied in many research finance fields, such as Engle and 
Manganelli(2004). Quantile regression complements the estimation of conventional mean models by providing a more sensitive insight into the distribution of the dependent variable by Magzamen et al. (2015). As presented by Fitzenberger and Wilke (2015), conventional modelling has focused on the mean of the dependent variable; quantile regression can detect whether the partial effect of a regressor on the quantile is the same for all quantiles or differs across quantiles.

\section{Methodology}

Quantile regression method can be applied to a wide range of applications in economics and finance. In quantitative investment, least square regression-based analysis is extensively used in analyzing factor performance, assessing the relative attractiveness of different firms, and monitoring the risks in their portfolios. Such methods are highly effective for understanding the central tendencies within a dataset, but are less powerful for understanding the behavior of data points close to the upper or lower extremes within a population. But from the perspective of an active investor or a risk manager, the tails of a relationship are often more immediately interesting than the central tendency. In statistics and the theory of probability, quantiles are points dividing the range of a probability distribution into contiguous intervals with equal probabilities, or dividing the observations in a sample in the same way. As an example, we illustrate how quantile regression method can provide a more nuanced analysis than is feasible with standard regression approaches in quantitative investment analysis.

The quantile regression model can be written as:

$$
\begin{gathered}
y_{t}=x_{t}^{\prime} \beta_{\theta}+u_{i} \text { with } \\
\text { Quant }_{\theta}\left(y_{t} \mid x_{i}\right)=x_{t}^{\prime} \beta_{\theta}
\end{gathered}
$$

where $y_{t}$ and $x_{t}$ denotes the returns of the stock market indices and the real estate indices and the $\beta_{\theta}$ is the vector of estimated

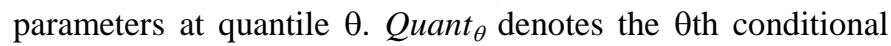
quantile of $y_{t}$ given $x_{t}$. The $\theta$ th regression quantile, $0<\theta<1$, is defined as a solution to the problem:

$$
\min =\frac{1}{T}\left[\theta \sum_{t ; y_{i} \geq x_{t}^{\prime} \beta_{\theta}}\left|y_{t}-x_{t}^{\prime} \beta_{\theta}\right|+(1-\theta) \sum_{t ; y_{i}<x_{t}^{\prime} \beta_{\theta}}\left|y_{t}-x_{t}^{\prime} \beta_{\theta}\right|\right]
$$

This is normally written as:

$$
\frac{1}{T} \sum_{t=1}^{T} x_{t}\left(\theta-\left\{\left|y_{t}-x_{t}^{T} \beta_{\theta}\right|\right\}\right)=0
$$

The problem does not have an explicit form, but can be solved by linear programming methods (Buchinski, 1994).

\section{DATA AND EMPIRICAL RESULTS}

Figure 1 shows the time patterns of the SSE government bond index and SSE composite index of Shanghai Exchange. Daily returns from January $2^{\text {nd }}$, 2003 to December $31^{\text {st }}, 2016$, including 3,399 trading days are obtained from CSMAR Database. The sample period starts from January $2^{\text {nd }}, 2003$ due to the SSE government bond index of China being launched this day. Table 1 shows some descriptive statistics for the log- returns of such data. The non-normality of the data is apparent from the coefficients of skewness and kurtosis. We can see that most of the return series shows signals of negative asymmetry. The kurtosis excess which shows positive asymmetry and leptokurtosis. Also, the Jarque-Bera test strongly rejects normality of the series of returns.

We apply the quantile regression estimation procedure to see the linkage of government bond and stock markets in China. Table 2 reports the estimated coefficients under the quantiles of $0.05,0.1,0.2,0.3,0.4,0.5,0.6,0.7,0.8,0.9$, and 0.95 .

A measure of the volatility, or systematic risk, of a security or a portfolio in comparison to the market as a whole. $\beta$ is used as the tendency of government bonds returns to respond to swings in the stock market. The coefficients of $\beta$ at quantile 0.05 is significantly negative. $\alpha$ is used to determine the abnormal returns of government bonds over the stock market expected returns. The coefficients of $\alpha$ at quantile $0.05,0.1,0.2$, $0.3,0.4$ and 0.5 are significantly negative and at quantile0.6, $0.7,0.8,0.9$, and 0.95 are significantly positive. Figure 2 shows the estimated coefficients under the quantile regression.

TABLE I. DESCRIPTIVE STATISTICS

\begin{tabular}{|c|r|r|}
\hline \multirow{2}{*}{ Table Head } & \multicolumn{2}{|c|}{ Return on Index(\%) } \\
\cline { 2 - 3 } & Government Bond & \multicolumn{2}{|c|}{ Stock } \\
\hline Mean & 0.038 & 0.014 \\
\hline Maximum & 9.455 & 1.019 \\
\hline Minimum & -8.841 & -1.373 \\
\hline Std. Dev. & 1.669 & 0.100 \\
\hline Skewness & -0.351 & -1.852 \\
\hline Kurtosis & 6.873 & 38.660 \\
\hline Jarque-Bera & $2194.417 * * *$ & $182035.400 * * *$ \\
\hline & a. The asterisks*** represents significance level at $1 \%$
\end{tabular}
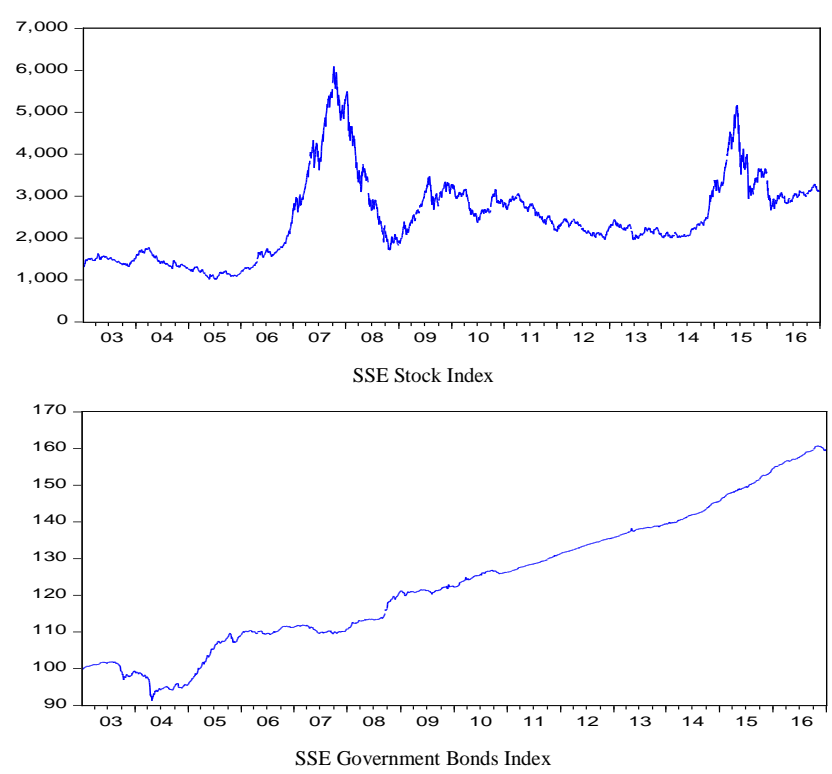

Fig. 1. Time patterns of index 
TABLE II. ESTIMATED COEFFICIENTS OF QUANTILE REGRESSION

\begin{tabular}{|c|c|c|}
\hline \multirow{2}{*}{ Quantile } & \multicolumn{2}{|c|}{ Return on Index(\%) } \\
\hline & $\boldsymbol{\alpha}$ & $\boldsymbol{\beta}$ \\
\hline 0.05 & $-5.281^{* * *}$ & $-0.672^{*}$ \\
\hline 0.1 & $-2.624^{* * *}$ & -0.238 \\
\hline 0.2 & $-1.778^{* * *}$ & 0.089 \\
\hline 0.3 & $-0.960^{* * *}$ & -0.106 \\
\hline 0.4 & $-0.520^{* * *}$ & 0.008 \\
\hline 0.5 & $-0.176^{* * *}$ & 0.051 \\
\hline 0.6 & $0.067^{* * *}$ & 0.070 \\
\hline 0.7 & $0.310^{* * *}$ & 0.059 \\
\hline 0.8 & $0.640^{* * *}$ & -0.104 \\
\hline 0.9 & $1.128^{* * *}$ & -0.305 \\
\hline 0.95 & $1.940^{* * *}$ & -0.732 \\
\hline \multicolumn{2}{|c|}{ b. The asterisks***and * represents significance level at $1 \%$ and $10 \%$, respectively. } \\
\hline
\end{tabular}
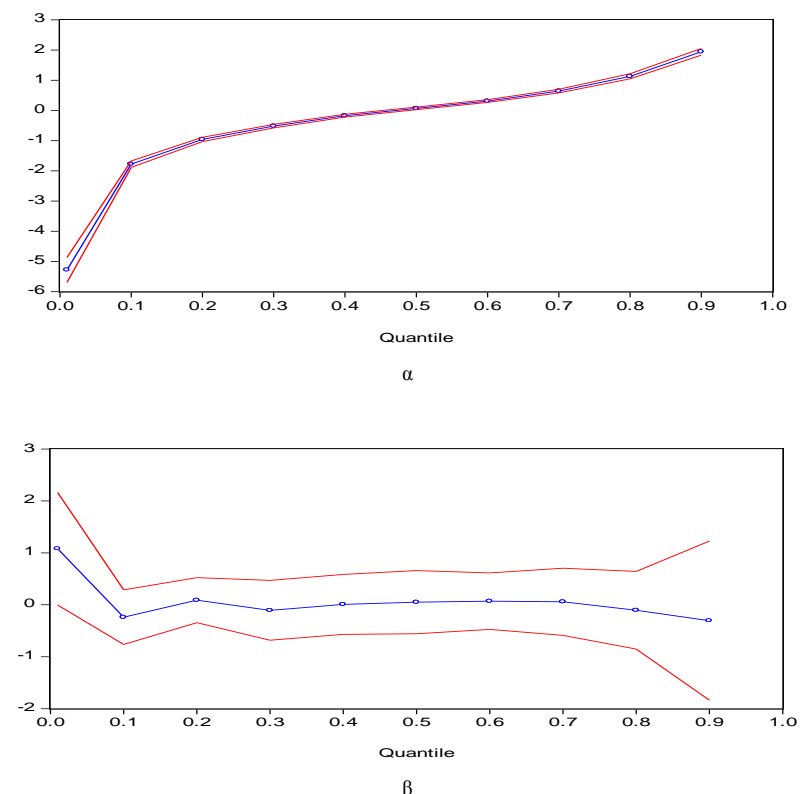

Fig. 2. Estimated coefficients under the Quantile Regression

\section{CONCLUSION}

We apply the quantile regression model to explore the linkage between price changes of government bonds and stock market returns in China. The quantile regression estimator is less sensitive to the presence of outlier observations, skewness, and heterogeneity on the response variable. Quantile regression is an extension of the standard regression, providing a complete picture of a conditional distribution. Compared to a traditional regression model, the quantile functions present more specific and accurate results. More precisely, as the quantile regression estimator minimizes the symmetrically weighted sum of absolute errors to estimate the conditional quantile function, other conditional quantile functions are estimated by minimizing an asymmetrically weighted sum of absolute errors, where the weights are functions of the quantile of interest. Moreover, quantile regression technique gives information on mean as well as the upper and lower tails. Thus, quantile regression is robust to the presence of outliers. Quantile regression is a powerful approach to examine the interrelationship between random variables. Indeed, the conditional quantile function of a scalar random variable is the inverse of its conditional distribution function. Therefore, quantile regression is a robust technique to examine the dynamic distributional change in time series, especially where the past information affects the location of the conditional distribution of dependent variable at a specified quantile.

The analysis of extreme quantiles observes that the linkage of government bond and stock markets is negative while the stock market at extremes. The results show that the linkage of stock market and government bond market may differ while the stock market is bearish or bullish.

The investor may consider the government bonds as a good financial hedge instrument while the stock markets are volatile. It is important for portfolio managers to be able to identify the circumstances in which there may be a change in the dependence between the returns of different assets to characterize the implications for portfolio diversification and asset allocation.

The institutional investors may synthetically invest government bond market and stock market. The linkage of the government bond and stock markets in China is worthwhile financial and economic issue for the investors who consider China equity market as the component of their portfolio.

\section{REFERENCES}

[1] A. B. Abel, "Stock prices under time-varying dividend risk. an exact solution in an infinite-horizon general equilibrium model,” in Journal of Monetary Economics , 1988, pp. 375-393.

[2] R. B.Barsky, "Why don't the prices of stocks and bonds move together," in American Economic Review, vol. 79, 1989,pp. 1132-1145.

[3] K. F. Chan, S. Treepongkaruna, R.Brooks and S .Gray, “Asset market linkages: evidence from financial, commodity and real estate assets,” in Journal of Banking \& Finance, vol. 35, 2011, pp. 1415-1426.

[4] L.Chollete, V. de la Peña, and C.-C. Lu, "International diversification: a copula approach,” in Journal of Banking and Finance, vol. 35, 2011,pp. 403-417.

[5] T.Chordia, A. Sarkar, and A. Subrahmanyam, "An empirical analysis of stock and bond market liquidity,” in Review of Financial Studies, vol. 18, 2005,pp. 85-129.

[6] R. Connolly, C. Stivers , and L. Sun, "Stock market uncertainty and the stock-bond return relation,” in Journal of Financial and Quantitative Analysis, vol. 40, 2005, pp. 161-194.

[7] R. Engle , and S. Manganelli, "CAViaR, Conditional autoregressive value at risk by regression quantiles," in Journal of Business and Economic Statistics, vol.22 2004, pp. 367-381.

[8] B. Fitzenberger, R. A. Wilke, Quantile Regression Methods. Emerging Trends in the Social and Behavioral Sciences: An Interdisciplinary, Searchable, and Linkable Resource, 2015, p.p.1-18. 
[9] J. Fleming, C. Kirby, and B. Ostdiek, "The economic value of volatility timing using realized volatility,” in Journal of Financial Economics, vol. 67, 2003,pp. 473-509.

[10] L.Gulko, “Decoupling,” in Journal of Portfolio Management, vol. 28, 2002, pp. 59-66.

[11] J.Gonzalo, and J. Olmo, "Contagion versus flight to quality in financial markets,” in Universidad Carlos III, Departamento de Economía, 2005.

[12] R.Goyenko, and S. Sarkissian, "Flight to liquidity and global equity returns,” in Working Paper, University Library of Munich, Germany, 2010.

[13] R. Koenker and G. Bassett, "Regression quantile,” in Econometrica, vol. 46, 1978, pp. 33-50.
[14] P.Hartmann, S. Straetmans, and C. G. d. Vries, "Asset market linkages in crisis periods,” in Review of Economics and Statistics, vol.86, 2004, pp. 313-326.

[15] K Kemper, A. Lee, and B. J. Simkins, “diversification revisited,” in Research in International Business and Finance, vol. 262 , 2012, pp. 304-316.

[16] S. Magzamen,M. S. Amato, P. Imm, J. A. Havlena, M. J. Coons, H. A. Anderson, C. F. Moore, "Quantile regression in environmental health: early life lead exposure and end-of-grade exams,” in Environmental. Reseach, vol. 137, 2015, p.p. 108-119.

[17] J. Piplack, and S.Straetmans, "Comovements of different asset classes during market stress,” in Pacific Economic Review, vol.15 , 2010,pp.385-400. 